Maryam MULIAEE

University of Colorado Boulder, USA

Department of Critical Media Practices

maryam.muliaee@colorado.edu

\title{
MEDIA-AS-THINGS: THE INTENSIFIED MATERIALITY OF DEGENERATED IMAGES
}

Recommended Citation: Muliaee, Maryam. "Media-as-things: The Intensified Materiality of Degenerated Images." Metacritic Journal for Comparative Studies and Theory 7.1 (2021): https://doi.org/10.24193/mjcst.2021.11.03

\begin{abstract}
This paper adopts an art-based research model to investigate how media objects, as entangled material agencies, can become co-creators with artists and condition the viewers' memory and imagination. My work Recycled Series among other artists' work are the subjects of this analysis. All these works involve images that are degenerated with a copy machine. The degenerated images lose coherence and become forms of ruins that the copier builds. Drawing from theories of things (Brown; Harman; Shaviro), I examine these works as the examples of "media-as-things" to show when media is misused, the potential of media is revealed. I place these works in the context of "broken-tech art" (Boym) and "haptic visuality" (Marks). I argue that these images determine a different object-subject relationship for their audience and their "thingness," which is intensified through degeneration effects, becomes a major factor in their aesthetic reception.
\end{abstract}

Keywords: Thing theory, Art-based research, Media-as-things, Broken-tech art, Degenerated image, Ruined image

\section{Introduction: The Material Turn}

In previous decades we have witnessed a turn to the material on both theoretical and practical grounds, followed by an upsurging interest in objects and their diverse roles, capacities and dynamics. The functions of mediation and the conditions of materiality have been of interest to both artists and scholars. The material turn, as Bruno Latour posits, can be associated with "the way we move knowledge forward in order to access things that are far away or otherwise inaccessible" (139). Calling attention to the 
matter of things has supported the framing for discourse, social relationships and experience. What is referred to as "the thing" may often be used synonymously with other terms such as "the object, matter, substance, the world, noumena, reality, appearance," for the philosophical history they all share; still, "through these various permutations, the thing remains identified with immanence," Elizabeth Grosz argues (124).

While since the Enlightenment period, the thing was positioned in a dualistic opposition to "the subject, the self, embodiment, or consciousness," new materialism redefines the thing through "its condition and the resource for the subject's being and enduring" (Grosz 124). One way to understand the agency of matter beyond this dualism is to acknowledge what Karen Barad has advocated as "intra-actions," a proposition that justifies the two-way relationship between all entities, which are more complex "between phenomena that are material, discursive, human, more-thanhuman, corporeal, and technological" (Alaimo and Hekman 5). In other words, not only do subjectivity, mind and memory depend on language and the social, but they are also formed through and in entangled relations with material things in the world. Acknowledging the premise of intra-actions "takes a radical rethinking of agency to appreciate how lively even 'dead matter' can be," Barad argues (419). This is also echoed in what Jane Bennett calls "vital materialism" - the idea that "every thing is entelechial, life-ly, vitalistic" (89). In this sense, theories of things are concerned with the ways in which the revelation of thingness challenges the existing discourse that separates the animates and inanimates, the subjects and objects, or the "mind and matter" in David Bohm's words (271).

How can the vibrancy of matter be embodied and interfaced for our experience and memories? If art is capable of undertaking this embodiment, what are some of the methods artists use to incorporate nonhuman actors-tools and objects-as agencies of memory and imagination in the creation process? "Those usually invisible thingsobjects and technical processes that make images, sounds, and written texts possible," as media scholar Timothy Barker argues, "are fundamental to understanding the efficacy of media" (4). With such a focus, a multiplicity of artistic works has demonstrated how "media can be understood or made to act differently in the face of emergencies" (Barker 4). Indeed, artists have been curious about the invisible sides of media-their thingness-and how the underlying materiality in tools and media technologies can be made visible for our perception and experience. 
Technology is one of the realms of "things" and the bedrock where questions of materiality arise. Considering the relationship between memory and the technical, I will draw from theories of things to explore the qualities of media objects as they become things in the work of art. Looking into some examples from my own media art practice Recycled Series to other artists' works, I examine the ways artists have used things and (the process of) thingness as conditions to co-create with nonhuman agencies for critical and aesthetic purposes.

\section{Media and Memory}

Memories and media are intertwined. Whether media technologies mediate our memories has been the subject of diverse arguments, particularly in the context of the digital (Hoskin; Blom et al; Ernst). While subjectivities and memories are drawn from many different sources, nevertheless “memories bear a certain technical nature," Amit Pinchevski argues (2). With the idea that memories are inevitably determined by the "technological structure" of media, one could justify that our "film-like" memories are not only driven from the content of cinema but also drawn from its "form." Media are not only bearers of messages but, importantly, are the material vehicles whose thingness twists the content they carry and transmit.

In what ways do techniques and technologies of imaging and representation mediate our recollections? In relation to memories, some authors like Joseph Brodsky and Susan Sontag, who have addressed the relationship between technical image and memory, both believe that the immediate images that come to mind (for instance, our recall of a place) are often the images we have already seen in films, photographs, and other visual media. "We retain not their three-dimensional image but their printed version;" in other words, "we remember not a place but our postcard of it" (Brodsky qtd. in Pallasmaa 23). In addition to the "situational and spatialized" aspects of memories, Finish theorist of architecture and place Juhani Pallasmaa underlines the mediating role of the technical image, arguing that "pictures, objects, fragments, and insignificant things, all serve as condensation centres for our memories" (23). Pallasmaa provides three reasons why images dramatically work as mnemonic devices: "first, they materialize and preserve the course of time and make it visible; second, they concretize remembrance by containing and projecting memories; and third, they stimulate and inspire us to reminisce and imagine" (18). 
Focusing on the relation between images and imaginations, Giuliana Bruno emphasizes the artists' acts of appropriating images - "digging, re-viewing, and revisioning in art" - which builds a visual depository and continually adds to the everincreasing archive of "variations and images" (40). Through these "mnemonic interactions" the visual and media arts "are capable of capturing temporality and memory." Taking media as both material objects and channels of representations, artistic works are means with which artists have created conditions to experience new memories, impacting the ways we envision and recall the world around us. As I will discuss later in this paper, sometimes intensifying and revealing the thingness in images becomes a condition to experience the artwork.

\section{Theories of Things}

What happens when media objects become things and fall outside their common course of communication and meaning? How do they become entangled entities in forming new subjectivities, memories and in providing an aesthetic experience? Theories of things are helpful to justify media art's profound interest in the materiality of technology.

Interestingly, Bill Brown ironically first coined the term "thing theory" in 2001 to argue that, unlike objects, things cannot be defined and escape theorization. Indeed, the thing theory he developed aims to clarify that things pose a problem of "specific unspecificity" (3). However, exactly through this obscurity, things could be distinguished from objects: "the very semantic reducibility of things to objects, [is] coupled with the semantic irreducibility of things to objects," in Brown's words (original emphasis). In contrast to objects, things escape the regular cycles of signification and representation that objects as everyday commodities pertain to. This division between things and objects is originally drawn from Heidegger's work and his idea of "broken tools." Heidegger specifies that when tools fail their common serviceability, expected use, and function, they fall out of their familiar circles of communication and meaning-they become things. For the purpose of this paper, I take tools as equivalent to media objects, to examine both images and technologies of imaging as things, when used in artistic works.

For philosophers and theorists of things, one of the significance of things lies in their possibility of revelation: things unveil some of the latent peculiarities (in objects) that could not be displayed and experienced otherwise. In this sense, the Heideggerian 
model suggests that tools (as objects) are entities existing with "a double life"-this binary account is nothing but "tool in action, [and] tool in disrepair," as described by Graham Harman (45). For Heidegger, this is the twofold profile of beings that determines their relationship and place in the world.

Equipment in action operates in an inconspicuous usefulness, doing its work without our noticing it. When the tool fails, its unobtrusive quality is ruined. There occurs a jarring of reference, so that the tool becomes visible as what it is (Harman 45).

The double life of tools implies that tools exist either in invisibility or visibility to our recognition. As long as tools work well and as expected, they remain unnoticeable for us. In this phase, being indistinguishable from many other common tools, devices and instruments that are fabricated to serve human needs, they "recede into the work of an unnoticed background" (Harman 44), and fade "into the universal referentiality of equipment" (Shaviro 50). Their other phase is the state of "eruption of absolute singularities," when they stop to work and fail to function as required tools. In this phase, they suddenly become "alive" (as things) and discernible to our awareness. When transformed into things, their "excess of being is suddenly revealed to us." In other words, broken tools arrest our attention and are experienced differently.

In drawing on Heidegger's account of things, and the distinction between things and objects, Brown pays more attention to what things can do and how they affect the existing discourses on subjectivities, rather than what things are and should be defined. For Brown, the peculiarity of things, suddenly appearing to our attention, sensual experience and perception, is "the story of a changed relation to the human subject" (4). Despite their problem of "unspecificity," "amorphous characteristic," or "irresolvable enigma," things seem to be indexed with some conspicuous qualities in Brown's observations and analogy, in which things are compared to "filthy windows" that make us "look at a window itself in its opacity" rather than looking through it (4). Moreover, there is an aspect of "suddenness" in our confrontation with things: "there are occasions of contingency-the chance interruption-that disclose a physicality of things" (4). Importantly, things do things to us. Brown underlines the affective and sensuous presence of things that can constitute human subjects. We encounter things in intense feelings of wonder, surprise, shock, melancholia, uneasiness, dread, and fear, amongst other feelings. 
In the contexts of art and literature, what things can do to other things and entities in their network, including us human subjects, becomes a key interest in Brown's investigation. In attention to thingness, Brown recites Walter Benjamin who sees "the gap between the function of objects and the desires congealed there," which leads to finding out that this contrast becomes more obvious "only when those objects became outmoded" (13). This quality fascinates artists and becomes an inspiration with which "art teaches us to see into things" (Benjamin qtd. in Brown 13).

The idea of broken tools could be very promising. However, because it imposes a dichotomy, Harman finds the Heideggerian model quite problematic. The problem in Heidegger's theory of broken tools lies in divorcing the two phases of visibility and invisibility for tool being. The "double movement" of tools approximates to the common dualistic view in which tools are regarded within "the inanimate-animate distinction" that, as Karen Barad condemns, is "one of the most persistent dualisms in Western philosophy and its critiques" (qtd. in Shaviro 62). Harman argues that "the broken/unbroken distinction does not function as an ontic rift between two different sorts of entities" (45). Do tools have to be smashed and fully inoperative (like the common example of "smashed-up blades and chisels") in order to reveal their beings? "Whether it is 'out of order' or not, the visible tool is simply not the tool in its being; in this way, insofar as they are ever encountered, all beings are broken equipment," Harman suggests (46).

To escape a model for things that appeals to a form of anthropocentrism, Harman argues that tools do not have to be regarded in a countermovement. Tools are not reducible to only their serviceability to humans but are beyond only humancantered usage and function. Harman extends Heidegger's theory to a more inclusive version, in order to resolve this dualistic divide, suggesting that tools do not need to be broken and smashed in terms of their standard usefulness to humans in order to reveal some of their singularities. In other words, the potential of tools goes beyond the context of only human-defined practicality, value, and effectiveness. Harman's statement supports this paper's argument, as I aim to explore art's ways of misusing media objects to incorporate nonhuman agencies without necessarily needing the objects to stop working completely. In discussing my artworks and other case studies in the next section, I show that when media are used in uncommon ways and beyond their intended purpose, they are capable of forming new subjectivities and memories. 
On the other hand, rather than aiming to reject the dualism in Heidegger's theory, Steven Shaviro reworks the idea of "broken tools" by adding a Whiteheadian perspective to it, to develop a productive version of the double movement of tools. The two phases of retreat and eruption in Shaviro's reading are entangled and point to a potential in tools: even when tools work well and seem to be dominated by their referential contexts, they are imbued with a potential-there is always something in tools that waits to be unleashed in specific circumstances. This acknowledgment means that tools are always entitled with a possibility: an agency to bring about something new-a form of "aesthetic event" in Shaviro's words, and, as informed by Whitehead, this can be "the basis of aesthetic attraction" (54) that is waiting ahead to be unfolded to our experience.

Retreat and eruption are both movements by means of which things demonstrate that there is more to them than we can gather about them. A thing can never be fully defined by any list, no matter how extended, of its characteristics and qualities, for beyond all these, it has its own autonomous power (Shaviro 52).

While in the context of everyday use tools organically break down due to usage, tools are also subject to artistic interventions to become aesthetic things. These artistic interventions can be placed in the context of thing theory. Adopting creative strategies to manipulate media objects and push tools to operate otherwise, artists have made works that exemplify "media-as-things" (Muliaee and Mehrvarz 156). The concept of media-as-things denotes the artworks in which consumer media objects are set to work differently and perform outside of their common tasks and operations. When media are forced to do other than their normal performance, they reveal some of their potential to us. In this sense, media-as-things is the art of making tools alive and revealing something new of technology's being. When thingness in media is amplified, artists become co-creators of their tools to condition audience memory and imagination. In the next section, I discuss how images can become things and determine a different object-subject relationship for the viewers. 


\section{Case Studies: Recycled Series and Other Examples}

My work, Recycled Series, consists of two videos in which I have used a black-andwhite digital copy machine to degenerate a series of images. In one of the pieces, I have degenerated a selection of images extracted from a compilation of ten short video clips. Each clip shows a ruined location in the world where it historically suffered severe war destruction, including Hiroshima and Nagasaki (Japan), Warsaw (Poland), Palmyra (Syria), and Bamian (Afghanistan), among others. In the second piece, I have selected a series of digital photographs taken inside a building that no longer exists. The building was demolished due to the state urban planning over the last three decades in the city and now remains as a vacant lot. In both works, I copied each image for several cycles until the final copied image was completely degenerated (see figure 1 and 2). When the process of copying (of a copy of a copy of a copy) is repeated for several successive runs, the image loses coherence and becomes hard to read. Through this xerographic technique, which is called degeneration, the copier transforms the representational characters in the image into abstract gray scale and monotone illegible patterns. The degenerated image is a ruined image built by the copy machine.
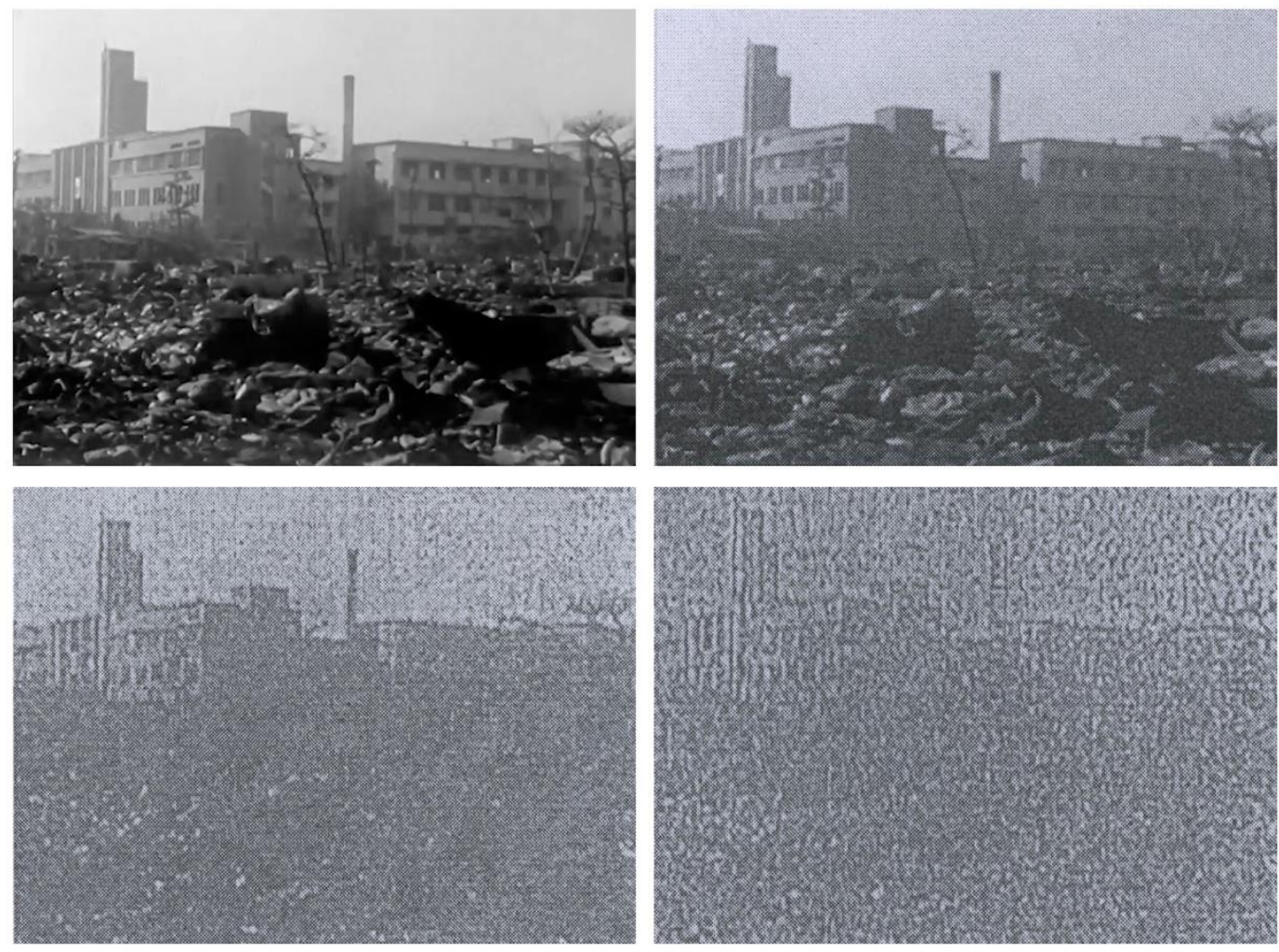

Figure 1. stills from Recycled Series, the image of some ruins in Japan after the atomic attack, and the degenerated images selected from different cycles of degeneration. Courtesy of the artist. 
What does the degenerated image disclose, and how does it mediate the viewers' memories? The degenerated images in Recycled Series play a game of doubles with the subject of ruins. Both the original clips/images and their degenerated versions represent different kinds of ruins: one, of the actual ruins-the actual places and urban scenes destroyed in the wars-and the other, of the ruins that the copier creates. Both ruins intensify our attention to what is disappearing in front of our eyes in the images. Recycled Series manifests that our images are never innocent. Our memories are mediated by technologies of reproduction without us noticing their agency and effects in regular moments. The moment when the copier goes away from the planned and expected course of duty, its potential is revealed to be seen. In these works, the copier becomes an active agent for creative means and the images become architectonic things disintegrated by the machine. The ruined images become things to contemplate with. What will we recall from these lost places whose images are degenerated by the copier and lost again in front of our eyes?
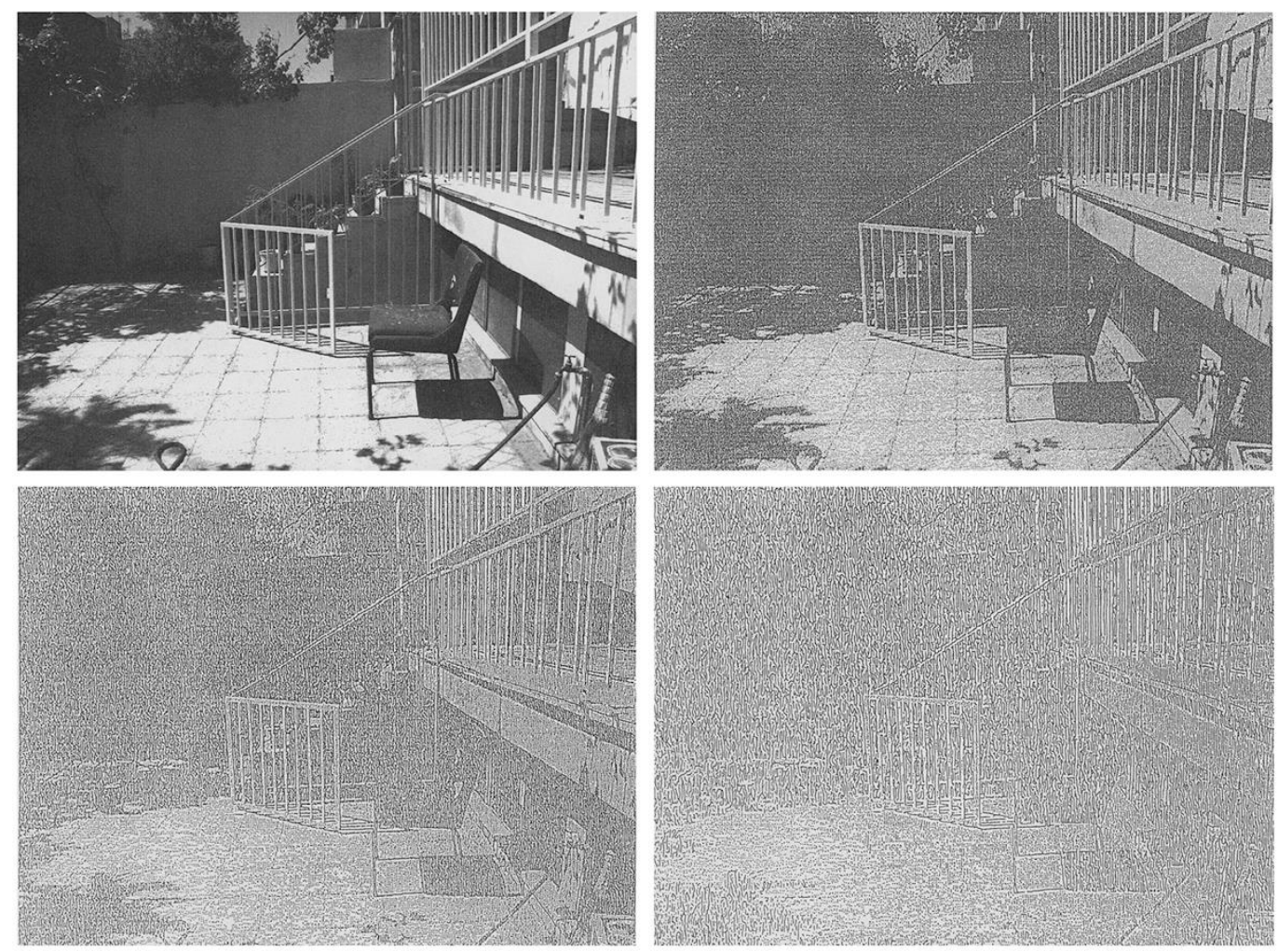

Figure 2. stills from Recycled Series, the image of the lost building, and the degenerated images selected from different copying cycles. Courtesy of the artist. 
Memory and imagination intercross in these images as the loss and absence are reinforced to govern the work for our experience. As we witness the images lose coherence, we acknowledge the copier's agency - its power of wiping out, erasure and re-inscription - that suddenly turns out to be discernible to our eyes and attention. This is the work of human and nonhuman agencies, both as collaborators making art. In this process, as the final copy becomes a new image, a new place (of different ruins) is built for our experience. New memories are generated as the audience sees the process of ruination take place in these images. With the plot of double ruins, new memories and subjectivities are invested in the degenerated images and one's imagination sparks to recall what is lost.

Moreover, Recycled Series challenges the discourse of the copy and the original not only with regard to the reproduced image but also with the technology of reproduction. The discourse of original and copy is one of the key points in Walter Benjamin's seminal essay “The Work of Art in the Age of Mechanical Reproduction.” In this text, Benjamin argues that reproductive media such as film and photography lack the aura (or the authenticity) that traditional arts such as painting and sculpture have. If aura is the originality-say, personality revealed in things-then it could be recognized in the quality of degenerated images that have become notably distinct from their original. In Recycled Series, not only is the loss of aura reversed (in the images due to degeneration effects), but a reversal of aura also occurs in the technology of reproduction per se that was used to work differently. In this work, the copier was revealed for its agency: to degenerate, to ruin, to erase. As a consumer technology, today often found in almost everyone's home or office, the copier is designed only to reproduce identical images and documents. However, in this work, the copier finds an aura when it is used paradoxically to fail at its own original designated task: to reproduce an image that should amount to its original. In this condition, when the copier is set to diverge from its common track, it becomes my co-creator in the artistic process of generating unique images. Revealing the latent energies of the erring apparatus, my work situates the copy machine as an agent of co-creation. The Recycled Series focuses our attention on the nonhuman agency, the other side of tools, and their failure. In the Recycled Series, technology's condition of perfection becomes almost impossible.

But my work does not come without predecessors. History of media art recounts the names of various artists who were interested in using their tools not only as 
consumer products but as active agents for critical and aesthetic purposes. German artist Timm Ulrichs used the degeneration technique to recycle the cover of Walter Benjamin's book in 100 runs in 1968, examining if the reproduction machine can ultimately change the meaning of a text. Exhibited as whole copies in a mural of 100 frames, the final copy in his work looked completely faded out and, as a non-pictorial image, bore no resemblance to the original book cover. In regard to Ulrichs' work, Hannah Frank calls our attention to artistic interventions that expose the potential and identities of technologies of reproductions. Artists like Ulrichs have contested and redefined xerographic tools particularly by exploring and engaging their agencies to creative ends.

Xerox is a corporation, a verb, a machine, a product, a promise, a threat. Ulrichs's photocopies may playfully tweak Benjamin, but the transformation of rigid text into something strange, amorphous, and unrecognizable recalls processes of decay and ruin. Xerox becomes an allegory (Frank 110).

With the same technique, in Systematically Altered Photographs (1968), Australian artist Ian Burn played with the conceptual effects of degenerated images. He selected three images from Australian Panorama, a magazine designed to promote tourism in Australia and then degenerated the images with a copier. The degeneration effects made the images intensely illegible, and erased their original meaning so they lacked any imagination or individuality for attracting tourists and travellers. Finally, each degenerated image was placed underneath the original photograph for view. One could think, Burn's work tries to ironically comment on Australia's history of colonialism. The degenerated images, based on the artist's remarks, could stand for anywhere settled and colonized in Australia.

Another artistic example of misusing imaging tools is the work of Canadian poet Derek Beaulieu who has used a photocopier to degenerate one of the scores of French composer Erik Satie. The original composition was written on one page in which Satie advised the players, "In order to play the theme 840 times in succession, it would be advisable to prepare oneself beforehand, and in the deepest silence, by serious immobilities" (qtd. in Beaulieu). Beaulieu degenerated the one-page composition and the whole process of degeneration took a total of 840 variations of the score over 10 book volumes. The final copy, which is totally degenerated, is an image that Beaulieu 
describes as "decomposed," and it opens up Satie's music to new meanings and interpretations. Here, the process of recycling that made the image illegible resonates with Satie's attempt for silence as a form of non-verbal communication.

In encountering an image that is progressively obscured and its "thingness" is intensified through degeneration effects, one is encouraged to contemplate the imperfection and unreliability of the machine. While technology always means to remain perfect and not deflect from what it is made to do, it is liable to fail. With a recognition that technology, like humans, is not always immune from failure and malfunction, artists have made works that embody their tools as an apparatus of variation. As the discussed works exhibited, the copier was capable of failing its original task and reveal the contingency of technological failure. These works give us a moment to contemplate how easy the agencies of our tools can be ignored or obscured in the name of technology's putative infallibility. Recycled Series (and the other examples discussed) interrogated the myth of the machine's perfection and let the technology perform as a broken technology.

\section{Broken-tech Art}

The discussed works presented how tools became things in the hands of artists and how artistic interventions revealed some of technologies' potential and effects. These strategies included forcing tools to depart their normalcy and do things aside from their usual function. In particular, the strategy I used to make the Recycled Series pairs with Svetlana Boym's concept of "broken-tech art" and unfolds a key implication of media-as-things.

Broken-tech art, one could argue, comes forth in the artists' reactions to the assumption that technology is above humans for accuracy and perfection. In creating broken-tech art, the artist has not followed the device's default instructions. As Boym describes, broken-tech art pertains to "nonconformist artists" (32) who take a critical approach to technology. By going awry and diverging from technology's practical usefulness, broken-tech art takes an alternative path to the myth of both technological progress and obsolescence, and redefines the media object through materializing its invisible agency. Looking at how artists worked against the standard uses of technology, Boym discusses Jacques Henri Lartigue's early-twentieth-century photographs as a relevant example of broken-tech art. Lartigue's photographs are blurry, incoherent, and erratic, because he intended to use the camera to capture 
time-the motions of people and machines in the city. "Instead of making his photographic subjects freeze in a perfect still, he captured them in motion, letting them evade his frame, leaving blurry overexposed shadows on the dark background" (Boym 31).

Lartigue's work is more than what one can immediately read on the surface of his photographs. It depicts a new, different relationship with technology. "Lartigue wanted photography to do what it cannot do, namely, capture motion" (31). Can media, as broken-tools, experience differently and as new? What does it imply for our experience when media objects do other than is expected and become media-asthings? Lartigue's intervention in photography's regular task of representation explored the potential in his camera for artistic goals. In this sense, broken-tech art could be a form of intervention: misusing everyday tools/objects and setting them to miscommunicate. In such a state, tools become media-as-things and reveal their agencies. For Boym, our encounter with technology in the moments they become things is significant: "Art's new technology is a broken technology" (73).

\section{Degenerated Images and the Challenge of Identification}

How do we experience the images whose visual clarities are dispersed on the surface and their representational characteristics dissipated, giving space instead to grains and textures? What kinds of identifications do images give rise to when their connection to the reality they index has been lost? Such images appeal to a form of "haptic visuality," to borrow Laura Marks' term (2). The haptic visuality, as Marks argues, is urged by "an image that is grainy, indistinct, or dispersed over the surface of the screen [and] invites a haptic look, or a look that uses the eye like an organ of touch" (104). Disintegrating filmic and photographic images could be some examples of haptic images. "Haptic images do not invite identification with a figure so much as they encourage a bodily relationship between the viewer and the image" (3). Likewise, the degenerated images in my work Recycled Series also can be read in line with the aesthetics of haptic images.

To elaborate on the conditions that can cause haptic visuality, Marks refers to the gradual decay and deterioration that happen organically in media such as chemical-based films and photographs, as well as magnetic tapes. These mediums all decay over time and their images (as well as sound) eventually fade out and disappear as they age. To put it in a different way, some media like cinema, arguably, have a 
"dying body" (95). The entropy in photographic, filmic or videographic images though happens naturally and slowly. Thus, artists and video-/filmmakers may adopt specific techniques to speed such deterioration in their images and make works that provide a tactile experience.

The images whose clarity and coherence are vanishing may encourage different kinds of subjectivities and identifications for their audience, as scholars have argued (Marks; Schwenger). For aging over time, cinema and photography have been associated with death, annihilation and mortality. Susan Sontag describes photography as one that "converts the whole world into a cemetery" (v). Cinema, too, has been posited as a medium of death: "to watch a film or video is to witness its slow death" (Marks 94). Experiencing an image that is dying may provide a dreadful identification with death and mortality of our own body, "as when we witness a disappearing image we may respond with a sense of our own disappearance" (94).

In this context, Roland Barthes' reflections on fading photographs and other counterarguments to his are inspiring. The point of departure for Barthes in evaluating photography is the eventual loss that occurs in the photographic image. "Attacked by light, by humidity, it fades, weakens, vanishes" (Barthes 93). In his seminal book, Camera Lucia, Reflections on Photography, Barthes describes the photograph as an object with a dying body, meditating the grief in looking at his mother's fading photograph: "Not only does it commonly have the fate of paper (perishable), but even if it is attached to more lasting supports, it is still mortal: like a living organism, it is born on the level of the sprouting silver grains, it flourishes a moment, then ages" (93).

Barthes examines the photography in relation to memory and, indeed, challenges the common conception of photography as a form of memory. Following the death of his mother, Barthes was meditating on some of her photographs, feeling that the photographs could give him "a sentiment as certain as remembrance" (70). However, because of the mortality of the photograph, it becomes for him a paradoxical object in relation to memory. Photography is "never, in essence, a memory," but on the contrary, "it actually blocks memory, quickly becomes a countermemory" (91). The identification with an image that gradually fades out and disappears could be a fearful identification with death. Barthes' radical response to this medium of loss, the photograph, is to reject it: "The only way I can transform the photograph is into refuse: either the drawer or the wastebasket. .... there is nothing left to do but throw it away" (93). 
In contrast to Barthes, others find this illegibility and lack of coherence in images somehow productive. In encounter with a degenerated image, "it is possible to identify with a dispersed subjectivity without dread," Marks argues (109). The dispersion of the pictorial representation on the surface of the image can activate the process of memory and be engaging a space of freedom for imagination and thought. Moreover, the fading photograph, as it becomes blurry and indistinct, appeals to a haptic look and encourages a multisensory experience; in this sense, it "draws us into a deep connection with all things, absent and present" (110). Marks gives examples of several artistic films/videos in which the artists have managed to "play with erased or barely visible video as an analogue for memory" (94). Artists' uses of decay and deterioration of the filmic/videographic images "borrow the aura of the disappearing images on which they meditate" as a reference to "memory loss." Thus, a haptic image could be a medium of unified bodies and new subjectivities.

A tactile look does not rely on a separation between looker and object as a more optical or cognitive look does. Because it does not rely on the recognition of figures, haptic looking permits identification with (among other things) loss, in the decay and partialness of the image. This sort of look, then, is not just about death, but about loving a living but noncoherent subject, an image that contains the memory of a more complete self (Marks 105).

According to Marks, the identification with the haptic image is not with "a coherent subject” but with the matter, nonhuman or inanimate objects and things. In other words, we possibly notice and identify with the material bodies of the haptic images per se. The history of experimental film enumerates works and practices that tended to engage with the materiality of filmic images. For instance, Stan Brakhage, Phil Solomon and Aldo Tambellini were among pioneer filmmakers who directly worked on the surface of their films, adopting strategies to accelerate film's process of decay. They made the material support of the cinema visible to audiences' eyes.

Likewise, in the Recycled Series, the sensory appeal of the images is considerable. In the practice with the copy machine, I have revealed and concretized the materiality of the images. The degenerated images are experienced for their thingness which is normally overshadowed by the images' representational content. In encountering the images in Recycled Series, the viewers experience an emergence: 
their look and attention are directed to the surface and textures-the affective materiality of the beholder. The degenerated images provoke new memories through loss and absence by appealing to the haptic visuality in which "the locus of identification and subjectivity is shifted from the human figure to an image dispersed across the surface of the screen" (Marks 94). In our encounter with haptic images as things, one's imagination is provoked and the process of memory is activated. In this sense, the images in Recycled Series become engaging.

\section{Conclusion}

Media are capable of becoming the artists' co-creators and conditioning the viewer's memories and imaginations. This paper has examined the examples of media-asthings-works in which the thingness in media objects is brought into play to provide new experiences, and subjectivities in the artistic works. When media objects are used to work in ways other than expected, their potential is revealed and that is the moment human and nonhuman agencies become collaborators in creative practice. In my work from the Recycled Series, I explored and incorporated the agential aspects of the copy machine as a reproduction tool into my work. I used the copier beyond its common duty and to degenerate images. This practice explored that ordinary tools are capable of becoming something else: things whose agencies are amplified and incorporated in the works of art.

Based on this work and other relevant artistic practices, I place the copier as an example of media-as-things. The concept of media-as-things points to the agential power of technology used for artistic co-creation and beyond regular practicality and common equipmental effects. On another level, I also place the degenerated images in the context of haptic visuality, as things that can direct our attention to their material support and reveal something invisible of their medium that we could not otherwise notice.

\section{References:}

Alaimo, Stacy, and Susan Hekman. Material Feminisms. Indiana University Press, 2008.

Barad, Karen. Meeting the Universe Halfway: Quantum Physics and the Entanglement of Matter and Meaning. Duke University Press, 2007. 
Barker, Timothy. "Between Emergence and Emergencies: An Introduction to the Special Issue 'Media, Materiality, and Emergency'.” MAST, 1.2 (2020): 3-22.

Barthes, Roland. Camera Lucida: Reflections on Photography. Macmillan, 1981.

Benjamin, Walter. "The Work of Art in the Age of Mechanical Reproduction.” Media and Cultural Studies: Keyworks. Ed. Meenakshi Gigi Durham and Douglas M. Kellner. Blackwell Publishing, 2001: 18-40.

Beaulieu, Derek. Vexations 2: Xerox Workcentre 5755. Canada, Ontario: Puddles of Sky Press, 2016.

https://derekbeaulieu.wordpress.com/2016/10/29/vexations-book-2-xeroxworkcentre-5755/. Accessed 2 March 2021.

Brown, Bill. "Thing Theory." Critical Inquiry 28. 1 (2001): 1-22.

Blom, Ina, Trond Lundemo and Eivind Røssaak. Memory in Motion: Archives, Technology and the Social. Amsterdam University Press, 2016.

Bohm, David. “A New Theory of the Relationship of Mind and Matter.” Philosophical psychology 3.2 (1990): 271-86.

Boym, Svetlana. The Off-modern. Bloomsbury Publishing, 2017.

Bruno, Giuliana. "Construction Sites: Fabricating the Architectural Imaginary in Art." Automatic Cities: The Architectural Imaginary in Contemporary Art, La Jolla, California: Museum of Contemporary Art San Diego, 2009: 37-55.

Burn, Ian. "Systematically Altered Photographs, 1968." Museum of Contemporary Art Australia, 1997. https://www.mca.com.au/artists-works/works/1997.74D/. Accessed 16 February 2021.

Frank, Hannah. Frame by Frame: A Materialist Aesthetics of Animated Cartoons. University of California Press, 2019.

Grosz, Elizabeth. "The Thing." The Object Reader. Ed. Fiona Candlin and Raiford Guins. Routledge, 2008: 124-38.

Harman, Graham. Tool-being: Heidegger and the Metaphysics of Objects. Open Court, 2011.

Hoskins, Andrew. Digital Memory Studies: Media Pasts in Transition. New York: Routledge, 2018.

Sontag, Susan. "Introduction." Portraits in Life and Death, by Peter Hujar. New York: Da Capo Press, 1976.

Latour, Bruno. “Can We Get Our Materialism Back, Please?” Isis, vol. 98.1 (2007): $138-42$. 
Marks, Laura U. Touch: Sensuous Theory and Multisensory Media. University of Minnesota Press, 2002.

Muliaee, Maryam and Mani Mehrvarz. "Fai(lure): Encounter with the Unstable Medium in the Work of Art." Miscommunication: Errors, Mistakes, and the Media. Ed. Maria Korolkova and Timothy Barker. Bloomsbury Publishing, 2021: 149-62.

Pallasmaa, Juhani. "Space, Place, Memory and Imagination: The Temporal Dimension of Existential Space." Spatial Recall: Memory in Architecture and Landscape, Ed. Marc Treib. London and New York, Routledge, 2013: 16-41.

Pinchevski, Amit. Transferred Wounds: Media and the Mediation of Trauma. Oxford University Press, 2019.

Schwenger, Peter. "Corpsing the image." Critical Inquiry, vol. 26. 3 (2000): 395413.

Shaviro, Steven. The Universe of Things: On Speculative Realism. University of Minnesota Press, 2014. 